\title{
Perceptions of Non-university Affiliated Dietetic Internship Program Directors Regarding Education Requirements to Obtain a Master's Degree as an Entry-level Dietitian
}

Abigail Sullivan

Central Michigan University, abys64@gmail.com

Roschelle A. Heuberger

Central Michigan University, heube1ra@cmich.edu

Follow this and additional works at: https://nsuworks.nova.edu/ijahsp

Part of the Dietetics and Clinical Nutrition Commons, and the Educational Leadership Commons

This Manuscript has supplementary content. View the full record on NSUWorks here:

https://nsuworks.nova.edu/ijahsp/vol15/iss3/9

\section{Recommended Citation}

Sullivan A, Heuberger RA. Perceptions of Non-university Affiliated Dietetic Internship Program Directors Regarding Education Requirements to Obtain a Master's Degree as an Entry-level Dietitian. The Internet Journal of Allied Health Sciences and Practice. 2017 Jan 01;15(3), Article 9.

This Manuscript is brought to you for free and open access by the College of Health Care Sciences at NSUWorks. It has been accepted for inclusion in Internet Journal of Allied Health Sciences and Practice by an authorized editor of NSUWorks. For more information, please contact nsuworks@nova.edu. 


\title{
Perceptions of Non-university Affiliated Dietetic Internship Program Directors Regarding Education Requirements to Obtain a Master's Degree as an Entry-level Dietitian
}

\begin{abstract}
Purpose: The Commission on Dietetic Registration announced that entry-level eligibility requirements to become a registered dietitian would increase to include obtaining a Master's degree. The objective of this study was to explore perceptions of non-university affiliated dietetic internship program directors regarding proposed education requirements. Methods: Directors participated in a phone survey of structured questions related to the topic. The population of focus was non-university affiliated dietetic internship program directors. Results: Program directors expressed viewpoints of positive, negative, and mixed regarding the increase in education requirements. Diversity and autonomy were among concerns expressed by program directors. Conclusion: The research found that this subset of stake holders remains conflicted with the decision by the Commission on Dietetic Registration that a Master's degree would be the entry-level requirement to become a registered dietitian.
\end{abstract}

\section{Author Bio(s)}

Abigail Sullivan, MS, RD, LDN is a corporate consultant dietitian in Chicago. An avid reader, she enjoys researching topics related to the role of the dietitian as it relates to global food security and disease prevention.

Dr. Roschelle Heuberger, PhD, RD is the Director of Graduate Programs in Nutrition and Dietetics at Central Michigan University. She completed her doctoral studies at the University of Wisconsin- Madison. She is the Chair of the Michigan Dietetic Educators and Preceptors and sits on the Board for the Medical Nutrition Council of the American Society of Nutrition. 


\title{
IUAHSP \\ The Internet Joưnal of Allied Health Sciences and Practice \\ Dedicated to allied health professional practice and education \\ Vol. 15 No. 3 ISSN 1540-580X
}

\section{Perceptions of Non-university Affiliated Dietetic Internship Program Directors Regarding Education Requirements to Obtain a Master's Degree as an Entry-level Dietitian}

\author{
Abigail Sullivan, MS, RD, LDN \\ Roschelle A. Heuberger, PhD, RD \\ Central Michigan University \\ United States
}

\begin{abstract}
Purpose: The Commission on Dietetic Registration announced that entry-level eligibility requirements to become a registered dietitian would increase to include obtaining a Master's degree. The objective of this study was to explore perceptions of nonuniversity affiliated dietetic internship program directors regarding proposed education requirements. Methods: Directors participated in a phone survey of structured questions related to the topic. The population of focus was non-university affiliated dietetic internship program directors. Results: Program directors expressed viewpoints of positive, negative, and mixed regarding the increase in education requirements. Diversity and autonomy were among concerns expressed by program directors. Conclusion: The research found that this subset of stake holders remains conflicted with the decision by the Commission on Dietetic Registration that a Master's degree would be the entry-level requirement to become a registered dietitian.
\end{abstract}

\section{INTRODUCTION}

The Commission on Dietetic Registration (CDR) announced in June 2013 that entry-level eligibility requirements to become a registered dietitian (RD) would increase to include obtaining a master's degree (MS) by 2024. ${ }^{1}$ The proposed changes will affect those dietetic internships (DI) that are not affiliated with a university and do not result in an MS following completion of the internship program. Programs that offer graduate credit and maintain an affiliation with a university were not surveyed. The purpose of this qualitative study was to collect information regarding perceptions held by non-university affiliated DI program directors regarding this change. Information was collected using a phone interview with a validated questionnaire. Program directors were asked, via phone interview, a series of questions to determine awareness and attitudes of the proposed changes to educational requirements. The primary objective was to understand the current viewpoints held by this group. This is a qualitative, approbatory, hypothesis generating study that provides stakeholder data. The research objectives involved $\mathrm{DI}$ director perceptions of proposed changes for increased education requirements.

\section{BACKGROUND AND SIGNIFICANCE}

The simplified equation to becoming an $\mathrm{RD}$ is an undergraduate degree in dietetics plus internship experience plus national exam. The pathways also allow for some deviation and several internships include the option to earn graduate credit or a graduate degree. Many internship programs remain with no affiliation to an academic institution in order to meet the increasing education requirements that include an MS.

There has been extensive discussion around the proposed change. A visioning report from the Academy of Nutrition and Dietetics (AND) Council on Future Practice (CFP) outlined the recommendation citing the need for dietitians to possess a knowledge base with a greater depth than that provided at the bachelor level of education. The report included implementation of nine recommendations for the future of the dietetics profession. A recommendation was made to elevate the educational requirements for the entry-level $\mathrm{RD}$ to include a minimum of a graduate degree and to require a graduate degree program that 
integrates coursework and supervised practice into one program based on core competencies. ${ }^{1}$ Following the report, the Accreditation Council for Education in Nutrition and Dietetics (ACEND) responded by releasing a rationale document for future education. ${ }^{2}$ ACEND ensures that educational institutions operate according to national standards. Since the inception of the organization, the emphasis of accreditation has shifted from specific mandatory coursework to include standards that focus on expected outcomes. Achievements of these outcomes are expected to be completed following the educational experience. Educators are the interpreters of those expected outcomes in creating course curriculum. ${ }^{3}$

Information gathered from stakeholders was Included in the rationale document from ACEND. These included employers, practitioners, educators, and students. Two questionnaires gathered input on skill sets from practitioners and importance of skill sets to employers. Additionally, performance of a competency gap analysis generated perspectives using feedback from focus groups. This determined expectations of entry level practitioner performance. From those sessions, moderators identified that an MS education for RDs is supported and that educational programs should incorporate transferable skills for additional professional tasks including leadership and management. From the results, recommendations to increase education requirements to include a graduate degree for entry-level RDs were developed. ${ }^{2}$

The debate to change education requirements includes discussions regarding current compensation for RDs. Among the top issues discussed was the increase in median hourly earnings for RDs from 2013 to 2015 . According to the most recent compensation and benefits survey of RDs, those working in pediatric/neonatal care showed an increase of $9.1 \%$ and in nutrition support, a $6.9 \%$ increase in earnings. ${ }^{4}$ These positions require participation with a team that includes allied healthcare professionals with advanced degrees and often require an MS as a requirement of application. The RD works with nursing staff as a part of the interdisciplinary team in the clinical setting, along with physicians, social workers, and physical, occupational, and speech therapists. All members could potentially have a vast range of education levels including a high school diploma to a doctorate degree.

In groups of heterogeneous individuals, a shared understanding of tasks is important for successful collaboration. ${ }^{5,6}$ This suggests a need to coordinate expertise to accomplish a shared goal. There are identified stages of interdisciplinary team development.7,8 At each stage, the level of education of team members impacts the individuals' qualities of prominence, sociability, and task orientation. Higher education levels are associated with an increase in these qualities among interdisciplinary healthcare teams. This is prominent in the early forming stages of a team. ${ }^{7}$

In $2015,52 \%$ of practicing RDs held an advanced degree while $17 \%$ of nurses in the same year held advanced degrees and $32 \%$ of nurses held leadership roles. ${ }^{4,9}$ The number of RDs that act as supervisors, either directly or indirectly, fell from $42 \%$ in 2013 to $39 \%$ in $2015.4,10$ However, dietetic students perceived themselves as leaders in a survey of undergraduate students. ${ }^{11}$ The need for leadership skills in the dietetic community continues to be an on-going discussion dating back decades and expands to include other members of the allied healthcare professionals. ${ }^{12-15}$ Nurses identified integrity, communication clarity, and problem solving ability as the top desired leadership qualities. ${ }^{14}$

\section{METHODS}

Prior to the start of the study, the researcher completed Good Clinical Practice and Basic Human Subjects coursework through the Collaborative Institutional Training Initiative. The research protocol was submitted to the Institutional Review Board (IRB) of the primary institution where the research was performed. It was deemed exempt from IRB oversight on January $30^{\text {th }}, 2015$, as the project did not meet the criteria for research on human subjects.

Directors of non-university affiliated Dls were chosen to participate in a one-time, non-incentivized phone interview. Inclusion criteria was based on the status of the program as being "non-affiliated" with an academic institution that could grant a master's degree upon completion of the internship program. Directors of programs with an affiliation with a university were excluded from the study. Director contact information was obtained from the publicly available list of dietetic internships on the Accredited Education Programs page of the website of The Academy of Nutrition and Dietetics (AND). Recruitment involved an initial email sent to this subset of internship directors ( 79 at the initiation of this study) describing the protocol for interviewing and the subject matter of questions to be asked. These questions were aimed at soliciting information regarding the proposed educational requirements for entry-level practice for RDs. Questions regarding their plans for the future to prepare graduating interns for a master's degree (MS) were developed. A validated questionnaire was developed using sequential focus groups of experts in the field, refining and revising questions through constant comparison techniques. The questionnaire was used to elicit information regarding future plans for graduating interns with an MS. Questions developed took level of participant understanding into account. Construct validity was established as questions were asked that targeted the same point but were phrased differently. See Table 1.

(c) The Internet Journal of Allied Health Sciences and Practice, 2017 
Table 1. Survey questions asked of dietetic internship directors

1. Are you familiar with the changes in eligibility requirements for entry-level RDs that will require a master's degree by 2024 ?

2. How do you feel about the change in eligibility requirements?

3. What do you foresee yourself doing in the future to meet these requirements?

4. Do you have an affiliation agreement with a university for interns to obtain a master's?

5. Does your program offer guidance for interns looking for placement into an existing master's program?

6. Would an online MS program appeal to your interns?

7. What qualities or characteristics would you want to see in a university in order to form an affiliation?

8. What characteristics would prevent you from forming an affiliation agreement with a university?

9. What is your opinion on how graduate coursework and supervised practice should be integrated or scheduled?

10. What is the composition of your current interns (age, gender)?

11. What percentage of your interns are originally dietetics majors?

12. What percentage plan to obtain a master's?

13. Have you been approached by a university?

14. Who would be contacted to propose an affiliation agreement?

15. Would an affiliation agreement with a university require a consensus among all preceptors?

A follow up email was sent to directors who did not respond to the initial request as a reminder to respond. After two email attempts, members of the research team called the internship directors to encourage participation. Those who agreed to participate in the study were contacted to set up a phone interview with the researcher, and emailed a consent form for review.

Semi-structured interviews were used to gain perspective regarding perceptions and information on the planning process for each DI. We asked questions regarding current program details, perceptions, and preparedness of proposed increasing requirements. We designed the survey questions to elicit both close-ended and open-ended responses.

All phone interviews were transcribed and formatted prior to exporting into qualitative analysis software Nvivo 10 to analyze content consistently with uniform coding and organization within the interviews. ${ }^{16,17}$ Themes among responses from the 28 interviews conducted were identified using word text search queries to generate a text frequency word cloud and themes were categorized as nodes. Frequently used words were assigned to a specific node based on the theme expressed. ${ }^{16}$ 


\section{RESULTS}

Variation and similarities were identified among attitudes of this subset of stakeholders. When asked an open-ended question "How do you feel about the change in eligibility requirements?" DI directors responded with positive, negative, and undecided expressions. Of the 27 directors, 9 expressed a positive association, 8 expressed a negative association, and 10 remained undecided. See Table 2 for excerpts from those directors that expressed a negative or positive view.

Table 2. Internship director response to question: "How do you feel about the change in eligibility requirements?"

\begin{tabular}{|c|c|}
\hline $\begin{array}{l}\text { Viewpoint } \\
\text { expressed }\end{array}$ & Response \\
\hline Positive & I do think that we need to be at a master's level for entry level. \\
\hline Negative & $\begin{array}{l}\text { "We are not paid so it doesn't matter what we have. If we're not reimbursed for our } \\
\text { services, it's doesn't matter if we have a PhD, we're not going to be utilized." }\end{array}$ \\
\hline Positive & $\begin{array}{l}\text { "I'm excited about the changes. I think it's a great idea for the profession to move } \\
\text { forward..." }\end{array}$ \\
\hline Negative & ".... I'll say that I do not love it..." \\
\hline Positive & $\begin{array}{l}\text { "I think that overall it will enhance the respect for our profession... I just don't think } \\
\text { that other disciplines understand us and what we can do, they still for whatever reason } \\
\text { associate us with food service workers..." }\end{array}$ \\
\hline Negative & "I do not necessarily agree with the requirements for an entry-level dietitian." \\
\hline Positive & $\begin{array}{l}\text { "... as a profession, we are needing to elevate our educational entry level requirements } \\
\text { to be more consistent with some of the other allied health professions." }\end{array}$ \\
\hline Negative & "I am opposed to the proposed model." \\
\hline Positive & "I feel that the master's level will definitely elevate the profession..." \\
\hline Negative & "...diverse populations will not be able to afford this change in requirements" \\
\hline Positive & $\begin{array}{l}\text { "I think it's very important for our profession to advance and I think the entry-level } \\
\text { master's requirements is a good thing." }\end{array}$ \\
\hline Negative & $\begin{array}{l}\text { "I think it's going to not help with the diversity problem we have in the program and I } \\
\text { think it's going to decrease the number of students that are really financially able to go } \\
\text { into the program." }\end{array}$ \\
\hline Positive & $\begin{array}{l}\text { "I've always felt that dietitians should have master's degrees and that we should move } \\
\text { forward with our education like our other peers in health are doing." }\end{array}$ \\
\hline Negative & "I'll say that I do not love it." \\
\hline Positive & "I think in general it's not a bad idea." \\
\hline Negative & $\begin{array}{l}\text { "I think that for the short term it's to reduce the number of slots there are for } \\
\text { internships and my concern is that hospitals aren't going to pay anymore for a dietitian } \\
\text { with a master's degree. You add all the cost of education and the student loans, are } \\
\text { you ever going to get that money back?" }\end{array}$ \\
\hline Positive & "I think overall, it's a good thing." \\
\hline
\end{tabular}

The directors expressing a positive association indicated that professionals would be more consistent with and receive more respect from other healthcare disciplines with an advanced degree. Other ideas centered on the knowledge base of the dietitian and the need for an advanced degree to maintain an adequate level of knowledge. Low entry-level salary for the RD was referenced as reasoning to increase education requirements in order to potentially increase salaries. Conversely, the directors expressing a negative association regarding the change in requirements cited concerns like additional education cost, low salary, and lack of diversity. DI directors felt that the return in entry-level salary would not match the additional education cost and thought the increased education would not result in an increase in salary. A concern with low levels of diversity within the profession was also mentioned throughout the interviews. Some DI directors remained undecided and voiced mixed feelings related to the proposed changes. 
When asked about the possibility of affiliating with a university to offer graduate credit, DI directors expressed concerns related to diversity and a loss of autonomy with their program. One director felt that "it will just be more of the best, the brightest, the whitest, and the richest..." if they affiliate with a university that selects their interns. Directors felt that diversity should be a priority when making intern selections and that they "...would probably look for a university that actively seeks students with cultural and ethnic diversity..." because the focus of their internship is "...developing RDs with cultural competence and language skills."

The selection of interns for the program was important to directors in addition to the ability to provide input into the curriculum and classes. The ability to remain autonomous was expressed when considering a potential affiliation agreement with a university. Directors were concerned about "...too much university oversight and control." When asked about qualities they would want to see in a university in order to affiliate, directors valued autonomy, different track options, online courses, affordability, and university reputation. Three directors indicated that they would not affiliate with a university with one voicing concern about their ability to ensure completion of coursework.

\section{DISCUSSION}

The questions posed to the directors in the survey remain and the responses invite new challenges for the future of the profession.

$$
\text { - As the profession evolves, what can be done to improve diversity? }
$$

Directors were on target when expressing concerns about diversity, as numbers are low in terms of gender with a 95\% female practitioner population. Additionally, $13 \%$ of practitioners identify as non-white. ${ }^{4}$ This is lower than the national reported workforce of $21 \%{ }^{18}$ and $25 \%$ of the nursing workforce identifying as non-white. ${ }^{19}$ In the US, patients that are non-English speaking experience better interpersonal care and have an increase in visit comprehension when seen by a practitioner with a shared language..$^{20}$

- How do stakeholders feel about the change in entry-level education requirements?

The frequency with which program directors remain undecided about their perception of the increasing education requirements is apparent. The fact remains that change within the profession is anticipated and educators that remain on the fence may be a barrier to a successful transition into the future for their programs, as many programs remain unaffiliated.

\section{CONCLUSION}

Overall, this presents new information to add to existing stakeholder data regarding the change in education level. The low sample size was a limitation for this research and future surveying of this subset of stakeholders is needed to verify the results. The inability to reach all DI directors within the time frame of the study contributed to the low sample size. The ability to do a repeat study would enhance validity of the results. This study was probatory with a goal of hypothesis generating, as there was no causality or inference. Due to the qualitative nature of the work, there is subjectivity involved and as a result it has to be put in the context of objective opinions about the study. Further research should include quantitative work to verify the results.

Some directors that were contacted were hesitant to participate in the survey. They stated that they were unsure of future plans and would therefore be unable to answer any questions regarding the topic. As more information is released for options for unaffiliated internship programs, more program directors may be willing to participate in such surveys to gather information on perceptions and preparedness. The information gathered may portray a better representation of this specific stakeholder group than the sample size reached in this survey.

\section{REFERENCES}

1. Academy of Nutrition and Dietetics Council on Future Practice. Visioning Report: Moving Forward - A Vision for the Continuum of Dietetics Education, Credentialing and Practice, 2012. Available at: https://www.cdrnet.org/vault/2459/web/files/10369.pdf. Accessed May 21, 2017.

2. Accreditation Council on Education in Nutrition and Dietetics. Rationale for future education preparation of nutrition and dietetics practitioners. ACEND Standards Committee Web site, 2015. Available at: https://www.cdrnet.org/vault/2459/web/files/10369.pdf http://www.eatrightacend.org/ACEND/content.aspx?id=6442485290. Accessed May 21, 2017. 
3. Winterfeidt EA, Bogle ML, Lea LE. Nutrition \& Dietetics: Practice and Future Trends, 4e. Burlington: Jones and Bartlett Learning; 2014.

4. Rogers D. Compensation and Benefits Survey 2015. J Acad Nutr Diet. 2016;116(3):370-88. [PMID: 26920236]

5. Bittner ACB, Leimeister JM. Creating Shared Understanding in Heterogeneous Work Groups: Why It Matters and How to Achieve It. J Manage Inform Syst. 2014;31(1):111-43.

6. Kleinsmann M, Valkenburg R. Barriers and enablers for creating shared understanding in co-design projects. Design Studies. 2008;29(4):369-86.

7. Farrell MP, Schmitt MH, Heineman GD. Informal roles and the stages of interdisciplinary team development. J Interprof Care. 2001;15(3):281-95. [PMID: 11705236]

8. Tuckman BW, Jensen MG. Stages of Small-Group Development Revisited. Group Organ Manage. 1977;2(4):419-27.

9. Bacon DR, Stewart KA. Results of the 2015 AORN salary and compensation survey. AORN J. 2015;102(6):561-74. [PMID: 26616315]

10. Rogers D. Compensation and Benefits Survey 2013. J Acad Nutr Diet. 2014;114(1):17-33. [PMID: 24342603]

11. Arendt SW, Gregoire MB. Dietetics students perceive themselves as leaders and report they demonstrate leadership in a variety of contexts. J Acad Nutr Diet. 2005;105(8):1289-94. [PMID: 16182648]

12. Boyce B. Learning to lead: developing dietetics leaders. J Acad Nutr Diet. 2014;114(5):688-92. [PMID: 24731524]

13. Gregoire MB, Arendt SW. Leadership: reflections over the past 100 years. J Acad Nutr Diet. 2004;104:365-403. [PMID: 14993862]

14. Delgado C, Mitchell MM. A survey of current valued academic leadership qualities in nursing. Nurs Educ Perspect. 2016;37(1):10-5. [PMID: 27164771]

15. Buckner EB, Anderson DJ, Garzon N, Hafsteinsdottir TB, Lai CKY, Roshan R. Perspectives on global nursing leadership: international experiences from the field. Int Nurs Rev. 2014;61:463-71. [PMID: 25411072]

16. NVivo qualitative data analysis Software, QSR International PTY Ltd. Version 10 [software], 2012. Available at: http://www.qsrinternational.com/nvivo-product. Accessed May 21, 2017.

17. Corbin J, Strauss A. Basics of Qualitative Research: Techniques and Procedures for Developing Grounded Theory, 4e. Thousand Oaks: SAGE Publications, Inc; 2015.

18. Bureau of Labor Statistics. Labor Force Characteristics by Race and Ethnicity, Nov 2015. Available at: http://www.bls.gov/opub/reports/race-and-ethnicity/archive/labor-force-characteristics-by-race-andethnicity-2014.pdf. Accessed May 21, 2017.

19. United States Department of Health and Human Services and Health Resources and Services Administration, 2013. The U.S nursing workforce: Trends in supply and education, 2013. Available at: http://bhpr.hrsa.gov/healthworkforce/reports/nursingworkforce/nursingworkforcefullreport.pdf. Accessed September 8, 2016.

20. Bureau of Health Professions, Health Resources and Services Administration, U.S. Department of Health and Human Services. The Rationale for Diversity in the Health Professions: A Review of the Evidence, 2006. Available at: http://bhpr.hrsa.gov/healthworkforce/reports/diversityreviewevidence.pdf. Accessed September 8, 2016. 